\title{
Lyell Syndrome with Fatal Outcome in Two Pregnant Women Receiving Antiretroviral Therapy in Guinea Conakry
}

\author{
Mohamed Cissé ${ }^{1}$, Mohamed Maciré Soumah ${ }^{1}$, Thierno Mamadou Tounkara ${ }^{1}$, Boh Fanta Diané ${ }^{1}$, \\ Fodé Bangaly Sack ${ }^{2}$, Houleymatou Baldé ${ }^{1}$, Amara Camara ${ }^{1}$, Aissata Dabo Camara ${ }^{1}$, \\ Alhousseini Doumbouya ${ }^{1}$
}

${ }^{1}$ Dermatology-STD, Donka Teaching Hospital, Gamal Abdel Nasser University of Conakry, Conakry, Guinea; ${ }^{2}$ Infectious and Tropical Diseases, Donka Teaching Hospital, Gamal Abdel Nasser University of Conakry, Conakry, Guinea.

Email: cissebibi@yahoo.fr

Received April 15 ${ }^{\text {th }}, 2013$; revised May $16^{\text {th }}, 2013$; accepted May 23 ${ }^{\text {rd }}, 2013$

Copyright (C) 2013 Mohamed Cissé et al. This is an open access article distributed under the Creative Commons Attribution License, which permits unrestricted use, distribution, and reproduction in any medium, provided the original work is properly cited.

\begin{abstract}
An old woman, 28 years old, weighing $74 \mathrm{~kg}$ was referred for skin detachment associated with bubbles and mucosal erosions. This clinical picture had occurred 15 days after the institution of a triple combination: AZT $(300 \mathrm{mg})+3 \mathrm{TC}$ $(150 \mathrm{mg})$ and nevirapine $(200 \mathrm{mg})$, during a pregnancy of 20 -week gestation. The woman was in her third gestation. The second case is aged 26, weighing $65 \mathrm{~kg}$. This clinical picture had occurred 20 days after the administration of a triple therapy combination: AZT $(300 \mathrm{mg})+3 \mathrm{TC}(150 \mathrm{mg})$ and nevirapine $(200 \mathrm{mg})$, during a pregnancy of 32-week gestation. It was the fourth gestation. The birth of a stillborn had occurred the day before his admission into our service. The diagnosis of Toxic Epidermal Necrolysis with nevirapine was selected on the basis of the clinical and anamnestic arguments. The biological tests showed the following results: transaminases (ALT and AST) were within normal limits, blood glucose, and urea $>10 \mathrm{mmol} / \mathrm{l}$. The evolution was marked by the patient death to Day 9 (D9) and at D2 of hospitalization. Discussion: NET and the SJS have been reported in pregnant women as potentially dangerous complications that are often associated with suspected drugs. Among these drugs, antiretroviral drugs, prescribed to pregnant women to prevent mother to child transmission of HIV are often reported. Our case is an illustration of the problem of HIV management in pregnant women. It also focuses on the association between pregnancy and Toxic Epidermal Necrolysis. Nevirapine is an effective drug in the regimens proposed in the management of HIV patients in limited resources countries. But the high frequency of toxidermia with this drug should lead to its replacement by other antiretrovirals least providers of toxidermia as anti proteases in the context of PMTCT programs.
\end{abstract}

Keywords: Lyell; Pregnant Women; Nevirapine; Fatal Outcome

\section{Introduction}

Lyell syndrome or Toxic Epidermal Necrolysis first described in 1956 by Allan Lyell [1] is a serious drug reaction characterized by extensive epidermal necrosis onset and rapid expansion.

The risk of cutaneous drug reaction is higher in patients infected with HIV than in the general population [2-4]. For a long time they were due mainly to sulfadoxin anti-infectious used to treat or prevent opportunistic infections $[3,4]$.

Since the occurrence of HAART, there is an additional risk of cutaneous toxicity associated with some of these drugs [5-7], mainly nevirapine. Indeed, several studies have documented the high incidence of drug-induced dermatitis induced by nevirapine [6-9].

This medicine is a component of most HAART proposed in sub-Saharan Africa. It plays a vital role in one of the public health priorities of the continent, the prevention of mother to child transmission (PMTCT) of HIV.

We report two cases of nevirapine induced TEN with fatal outcome in two pregnant women having received it in the context of prevention of mother to child transmission of HIV.

\subsection{Observation 1}

An old woman, 28 years old, weighing $74 \mathrm{~kg}$ was referred 
to the Department of Dermatology-STD, Donka Teaching Hospital, by a PMTCT center of Conakry, for skin detachment associated with bubbles and a mucosal erosions.

This clinical picture had occurred 15 days after the institution of a triple combination: AZT $(300 \mathrm{mg})+3 \mathrm{TC}$ $(150 \mathrm{mg})$ and nevirapine $(200 \mathrm{mg})$, during a pregnancy of 20 -week gestation. The woman was in her third gestation.

At examination, there was a poor general condition, bullous eruption with flaccid bullae of clear content, a sign of Nikolski, erosive and oozing closets, an epidermal detachment with a surface of skin detachment covering up to $60 \%$ of the body surface area (BSA) (Figure 1). There was also mucosal erosions (oral, conjunctival and genital). CD4 cell count at baseline was 337 cells $/ \mathrm{mm}^{2}$. Viral load was not performed. Diagnosis of Toxic Epidermal Necrolysis was selected on the basis of clinical evidence.

Laboratory tests performed (urea, glucose and bicarbonate) in addition to clinical factors gave a SCORTEN of 5 with a predictive mortality of $90 \%$. Transaminases (ALT and AST) and other haematological investigations were normal.

During hospitalization, she gave birth to a premature male baby weighing $700 \mathrm{~kg}$ who has been admitted in neonatology.

The evolution was marked by the death of the patient to Day 9 (D9) of hospitalization. The baby also died at D2 neonatal hospitalization.

\subsection{Observation 2}

This woman aged 26, weighing $65 \mathrm{~kg}$, was referred to the Department of Dermatology-STD, Donka Teaching Hospital, by a peripheral PMTCT center, for skin detachments associated with bubbles and a mucosal erosions.

This clinical picture had occurred 20 days after the

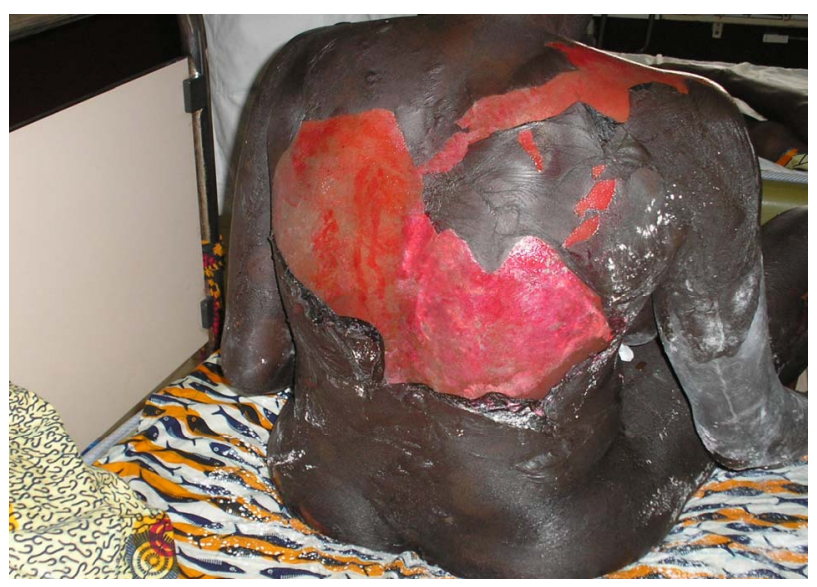

Figure 1. Surface of skin detachment covering up to $60 \%$ of the body surface area (BSA). administration of a triple therapy combination: AZT (300 $\mathrm{mg})+3 \mathrm{TC}(150 \mathrm{mg})$ and nevirapine $(200 \mathrm{mg})$, during a pregnancy of 32-week gestation. It was the fourth gestation. The birth of a stillborn had occurred the day before his admission into our service.

At examination, there was flaccid bullae of clear content, a sign of Nikolski, closets erosive and oozing, epidermal detachment with an estimated surface of $70 \%$ of the body surface area. There was also a mucosal (oral, conjunctival and genital) lesions in type croûto-erosive and oozing. CD4 cell count at baseline and viral load were not performed. Other hematological and biochemical examinations were normal.

The diagnosis of Toxic Epidermal Necrolysis with nevirapine was selected on the basis of the clinical and anamnestic arguments. The biological tests showed the following results: transaminases (ALT and AST) were within normal limits, blood glucose, and urea $>10$ $\mathrm{mmol} / \mathrm{l}$. These elements corresponded to a SCORTEN of 4. The evolution was marked by the patient death at D2 of hospitalization.

\section{Discussion}

Lyell syndrome or Toxic Epidermal Necrolysis (TEN) is the most common and most serious adverse drug reaction. It is a real public health problem because of its high mortality and its important functional impact. Its occurrence during pregnancy is increasingly reported [10$13]$.

Since its first description, the detailed pathogenesis of this syndrome is not yet completely understood. Immune modulation and different forms of metabolism of drugs and other factors have been suggested [1,14].

According to some authors, the pregnancy itself could possibly induce NET/SSJ by complex immunomodulatory reactions, but pathophysiologic details remain obscure $[12,15]$. Others authors [16] have reported Toxic Epidermal Necrolysis cases during pregnancy with no direct connection with any drug or specific infection.

NET and the SJS has been reported in pregnant women as potentially dangerous complications that are often associated with suspected drugs. Among these drugs, antiretroviral drugs, prescribed to pregnant women to prevent mother to child transmission of HIV are often reported.

Toxidermia Frequency due to nevirapine varies between 10 to 35 percent according to studies [5,9,17-22]. In a meta-analysis of different cohorts under nevirapine, the frequency of drug-induced dermatitis, regardless of severity, was estimated at 35 percent in 380 patients treated with nevirapine against 19 percent in the control group [17]. In the same population, toxidermia were severe in 6.6 percent in the nevirapine group against 1,9 percent in the control group. The frequency of serious 
toxidermia due to nevirapine varies according to the authors. Indeed, if in the majority of cases toxidermia induced by nevirapine are benign and are largely dominated by maculopapular exanthema, the frequency of severe toxidermia is not egligible [7,23,24]. The risk of $\mathrm{SJS} / \mathrm{TEN}$ patients treated with nevirapine is 0.3 percent [7].

The degree of immune deficiency associated with taking nevirapine would play a role in the occurrence of TEN in pregnant women. Indeed, according to Boehringer Ingelheim [25], the manufacturer of nevirapine, there would be an increased probability of liver as well as skin toxicity in HIV-infected women in general, taking this medicine with CD4 counts greater than $250 / \mathrm{mm}^{3}$, as in the case we report. For some authors a CD4 count $<100 \mathrm{~mm}^{3}$ increase the risk of cutaneous drug reaction [25], for others it is the opposite [26,27].

Premature birth and low weight birth observed in our case, have been reported by other studies. Indeed, premature births and fetal hypotrophy are more common in cohorts of women infected with HIV than in the general population [28], and several other cohorts showed an increased rate of preterm delivery associated with the use of HAART [29-31]. This finding remains unexplained pathophysiologically, and we can not say whether there is a causal link between antiretroviral therapy and preterm delivery [16]. Preterm birth in Lyell's syndrome itself could be due to fetal stress due to the illness of the mother [15].

Although the treatment is largely symptomatic, Toxic Epidermal Necrolysis in pregnant woman is a challenge for the entire medical team, especially at an early stage of gestation. The mortality rate is very high during Toxic Epidermal Necrolysis and turn out to approximately 40 percent [1]. Paradoxically, the literature suggests a high rate of survival of the mother and the newborn in cases of Lyell's syndrome during pregnancy, this could be the result of publication bias [16].

\section{Conclusions}

Our case is an illustration of the problem of HIV management in pregnant women. It also focuses on the association between pregnancy and Toxic Epidermal Necrolysis.

Nevirapine is an effective drug in the regimens proposed in the management of HIV patients in limited resources countries. But the high frequency of toxidermia with this drug should lead to its replacement by other antiretrovirals least providers of toxidermia as anti proteases in the context of PMTCT programs.

\section{REFERENCES}

[1] A. Lyell, "Toxic Epidermal Necrolysis: An Eruption Resembling Scalding of the Skin," British Journal of Der- matology, Vol. 68, No. 11, 1956, pp. 355-361. doi:10.1111/j.1365-2133.1956.tb12766.x

[2] S. A. Coopman, R. Johnson, R. Platt, et al., "Cutaneous Diseases and Drug Reactions in HIV Infection," The New England Journal of Medicine, Vol. 328, No. 23, 1993, pp. 1670-1674.

[3] A. Carr, C. Swanson, R. Penny, et al., "Clinical and Laboratory Markers of Hypersensitivity to TrimethoprimSulfamethoxazole in Patients with Pneumocystis Carinii Pneumonia and AIDS," The Journal of Infectious Diseases, Vol. 167, No. 1, 1993, pp. 180-185.

doi:10.1093/infdis/167.1.180

[4] A. Carr, B. Tindall and D. A. Cooper, "Patterns of Multiple Drug Hypersensitivity in HIV-Infected Patients," AIDS, Vol. 7, No. 11, 1993, pp. 1532-1533. doi:10.1097/00002030-199311000-00023

[5] B. Milpied-Homsi, V. Relliquet, A. Huart, et al., "Skin Toxicity of Nevirapine Used as First-Line Treatment 100 Patients," Annales de Dermatologie et de Venereologie, Vol. 126, 1999, p. 2S21.

[6] D. Halvir, S. H. Cheeseman, M. McLaughlin, et al., "High-Dose Nevirapine: Safety, Pharmacokinetics and Antiretroviral Effect in Patients with HIV," The Journal of Infectious Diseases, Vol. 171, No. 3, 1995, pp. 537545. doi:10.1093/infdis/171.3.537

[7] J. P. Fagot, M. Mockenhaupt, J. N. Bouwes-Bavinck, et al., "Nevirapine and the Risk of Stevens-Johnson Syndrome or Toxic Epidermal Necrolysis," AIDS, Vol. 15, No. 14, 2001, pp. 1843-1848.

doi:10.1097/00002030-200109280-00014

[8] R. T. d'Aquilla, M. D. Hughes, V. A. Jonhson, et al., "Nevirapine, Zidovudine, and Didanosine Compared with Zidovudine and Didanosine in Patients with HIV-1 Infection," Annals of Internal Medicine, Vol. 124, No. 12, 1996, pp. 1019-1030. doi:10.7326/0003-4819-124-12-199606150-00001

[9] A. Barner and M. Myers, "Nevirapine and Rashes," Lancet, Vol. 351, No. 9109, 1998, pp. 1133-1134. doi:10.1016/S0140-6736(05)79417-4

[10] B. Diatta, F. F. D. Ly, N. F. Ngom, C. T. Cissé, F. Fall, et al., "Toxidermia with Névirapine during Pregnancy about 3 Cases Report," Annales de Dermatologie et de Venereologie, Vol. 138, No. C50, 2011, p. S54.

[11] A. Shilad, M. Predanic, S. C. Perni, et al., "Human Immunodeficiency Virus, Pregnancy and Stevens-Johnson Syndrome," Obstetrics \& Gynecology, Vol. 105, No. 5, 2005, pp. 1254-1256. doi:10.1097/01.AOG.0000157766.49494.99

[12] I. C. Niemeijer, M. C. Van Praag and N. Van Gemund, "Relevance and Consequences of Erythema Multiforme, Stevens-Johnson Syndrome and Toxic Epidermal Necrolysis in Gynecology," Archives of Gynecology and $\mathrm{Ob}$ stetrics, Vol. 280, No. 5, 2009, pp. 851-854. doi:10.1007/s00404-009-1008-1

[13] K. Kratzert, F. Marks, C. Antoine, et al., "Pregnancy Post Stevens-Johnson Syndrome: Case Report and Review of the Literature," Obstetrics \& Gynecology, Vol. 72, No. 3, 1988, pp. 447-450. 
[14] W. H. Chung, S. I. Hung, J. Y. Yang, et al., "Granulysin is a Key Mediator for Disseminated Keratinocyte Death in Stevens-Johnson Syndrome and Toxic Epidermal Necrolysis," Nature Medicine, Vol. 14, No. 12, 2008, pp. 1343-1350. doi: $10.1038 / \mathrm{nm} .1884$

[15] N. Claessens, L. Delbeke, J. Lambert, et al., "Toxic Epidermal Necrolysis Associated with Treatment for Preterm Labor," Dermatology, Vol. 196, No. 4, 1998, pp. 461-462. $\underline{\text { doi: } 10.1159 / 000017950}$

[16] M. F. Struck, T. Liss, Y. Illert, et al., "Toxic Epidermal Necrolysis in Pregnancy: Case Report and Review of the Literature," Journal of Burn Care \& Research, Vol. 31, No. 5, 2010, pp. 816-821. doi:10.1097/BCR.0b013e3181eed441

[17] R. B. Pollard, P. Robinson and K. Dransfield, "Safety Profile of Nevirapine a Nonnucleosid Reverse Transcriptase Inhibitor for the Treatment of HIV," Clinical Therapeutics, Vol. 20, No. 6, 1998, pp. 1071-1092. doi:10.1016/S0149-2918(98)80105-7

[18] H. Knobel, J. M. Miro, P. Domingo, et al., "Failure of Short-Term Prednisone Regimen to Prevent Nevirapine Associated Rash: Double-Blind Placebo-Controlled Trial, the GESIDA09/99 Study," Journal of Acquired Immune Deficiency Syndromes, Vol. 28, No. 1, 2001, pp. 14-18.

[19] A. Carr, S. Vella, MD. de Jong et al., "A Controlled Trial of Nevirapine Plus Zidovudine alone in p24 Antigenaemic HIV-Infected Patients. The Dutch-Italian-Australian Nevirapine Study Group," AIDS, Vol. 10, No. 6, 1996, pp. 635-641. doi:10.1097/00002030-199606000-00009

[20] J. S. Montaner, P. Reiss, D. A. Cooper, et al., “A Randomized, Double Blind Trial Comparing Combinaisons of Nevirapine, Didanosine and Zidovudine for Hivinfected Patients: The INCAS Trial," JAMA, Vol. 279, No. 12, 1998, 930-937. doi:10.1001/jama.279.12.930

[21] F. Lawson-Ayayi, R. Thiebaut, R. Ramanampamonjy, et al., "A Cohort of Nevirapine Tolerance in Clinical Practice: French Aquitaine Cohort 1997-1999," Clinical Infectious Diseases, Vol. 35, No. 10, 2002, pp. 1231-1237. doi: $10.1086 / 343046$

[22] E. Caumes, P. Bossi, C. Katlama, et al., "Antiretroviral Drug Eruption to Patients Infected with HIV," La Presse Médicale, Vol. 32, No. 28, 2003, pp. 1325-1333.

[23] A. Rotunda, R. J. Hirsch, N. Scheinfeld, et al., "Severe
Cutaneous Reactions Associated with the Use of Human Immunodeficiency Virus Medications," Acta DermatoVenereologica, Vol. 83, No. 1, 2003, pp. 1-9. doi:10.1080/00015550310002611

[24] Y. Bourezane, D. Salard, B. Hoen, et al., "DRESS (Drug Rash with Eosinophilia and Systemic Symptoms) Syndrome Associated with Nevirapine Therapy," Clinical Infectious Diseases, Vol. 27, No. 5, 1998, pp. 1321-1322.

[25] V. Kohlbrenner, K. Dansfield, V. Cotton, et al., "Cutaneous Eruptions Associated with Nevirapine Therapy in HIV-1 Infected Patients Individuals (Abstract MoB 12021)," 10th International Conference on AIDS, Vancouver, 7-12 July 1996, p. 607.

[26] J. S. Montaner, P. Cahn, C. Zala, et al., "Randomized, Controlled Study of the Effects of Short Course of Prednisone on the Incidence of Rash Associated Nevirapine in Patients Infected with HIV-1," Journal of Acquired Immune Deficiency Syndromes, Vol. 33, No. 1, 2003, pp. 41-46. doi:10.1097/00126334-200305010-00007

[27] S. J. Bersoff-Matcha, W. C. Miller, J. A. Aberg, et al., "Sex Differences in Nevirapine Rash," Clinical Infectious Diseases, Vol. 32, No. 1, 2001, pp. 124-129. doi: $10.1086 / 317536$

[28] P. Brocklehurst and R. French, "The Association between Maternal HIV Infection and Perinatal Outcome: A Systematic Review of the Literature and Meta-Analysis," British Journal of Obstetrics and Gynaecology, Vol. 105, No. 8, 1998, pp. 836-848. doi:10.1111/j.1471-0528.1998.tb10227.x

[29] European Collaborative Study, "Swiss Mother and Child Cohort Study: Combination Antiretroviral Therapy and Duration of Pregnancy," AIDS, Vol. 14, No. 18, 2000, pp. 2913-2920. doi:10.1097/00002030-200012220-00013

[30] E. G. Szyld, E. M. Warley, L. Freimanis, et al., "Maternal Antiretroviral Drugs during Pregnancy and Infant Low Birth Weight and Preterm Birth," AIDS, Vol. 20, No. 18, 2006, pp. 2345-2353. doi:10.1097/01.aids.0000253362.01696.9d

[31] A. M. Cotter, A. G. Garcia, M. L. Duthely, et al., "Is Antiretroviral Therapy during Pregnancy Associated with an Increased Risk of Preterm Delivery, Low Birth Weight, or Stillbirth?" The Journal of Infectious Diseases, Vol. 193, No. 9, 2006, 1195-1201. doi:10.1086/503045 